\title{
OTR7 - ANÁLISE DE RISCOS PARA PRIORIZAR AUDITORIAS EM FORNECEDORES DE MATERIAL DE EMBALAGEM SECUNDÁRIA: O ESTUDO DE CASO BIO-MANGUINHOS
}

$\underline{\text { Jorge Ricardo Silva Moreira }^{1}}$, José Manuel Santos de Varge Maldonado ${ }^{2}$, Elezer Monte Blanco Lemes ${ }^{3}$.

1. Bio-Manguinhos, Fundação Oswaldo Cruz, Divisão de Auditorias e Treinamentos, Departamento de Garantia da Qualidade, Rio de Janeiro, Brasil.

2. Escola Nacional de Saúde Pública, Fundação Oswaldo Cruz, Rio de Janeiro, Brasil.

3. Bio-Manguinhos, Fundação Oswaldo Cruz, Vice Diretoria de Produção, Rio de Janeiro, Brasil.

Objetivo: Este trabalho apresenta a análise da qualificação de fornecedores de material de embalagem secundária (bulas, cartuchos e rótulos) de Bio-Manguinhos, frente às necessidades técnicas, regulatórias, normativas e operacionais bem como dos riscos associados à qualidade final dos produtos.

Metodologia: Um estudo de caso conduzido por pesquisa bibliográfica e documental, onde foram levantados dados para análise dos processos de pré-qualificação, qualificação de fornecedores de embalagem secundária e históricos das análises do controle de qualidade. Este estudo avaliou a lista de verificação utilizada por Bio-Manguinhos como ferramenta para Pré-Qualificação de Fornecedores desses materiais, estabeleceu critérios para classificação de graus de criticidade, de forma a estabelecer classificação e pontuação para cada item da lista de verificação e ainda apresentou ferramenta de gestão de risco Risk Ranking and Filtering (RRF) para definição de periodicidades das auditorias e das ações de acompanhamento do processo de Qualificação de Fornecedores.

Resultados: Uma proposta da lista de verificação com pontuação para classificação por grau de criticidade ao produto/processo e proposta de critérios de priorização das auditorias de Qualificação de Fornecedores de material de embalagem e das ações de acompanhamento, a partir da aplicação de ferramenta de gestão de risco $R R F$ definindo os casos de auditoria anual, bianual, formas de planejamento e execução. A avaliação dos fornecedores proporcionou um racional estruturado para a tomada de decisão quanto 
priorização e alocação de recursos, tendo como resultado a definição da execução de três auditorias bianuais completas (dois de bulas e um de cartucho), quatro anuais de adequação (três de rótulos e um de cartucho), priorizando os processos de avaliação da conformidade que envolvem reclamações, investigação de desvios e duas auditorias anuais completas (dois de cartuchos) para os mais críticos dos estudados.

Conclusão: O estudo de caso demonstrou a importância de trabalhar os critérios utilizados para avaliação da conformidade nos processos de aquisição, importância das análises de controle de qualidade e da utilização da ferramenta $R R F$ para a priorização de auditorias em fornecedores, propondo como recomendações ampliação deste trabalho aos demais fornecedores e integração dos processos de aquisição e qualificação para avaliação da conformidade de fornecedores. 